Journal of Molecular Structure, 65 (1980) 141-152

Elsevier Scientific Publishing Company, Amsterdam - Printed in The Netherlands

\title{
CALCULATION OF THE IN-PLANE FORCE CONSTANTS AND VIBRATIONAL SPECTRA OF PYRIDINE AND ITS DEUTERATED DERIV ATIVES BY THE CNDO/2 FORCE METHOD
}

\section{HARSÁNYI}

Hungarian Academy of Sciences, Research Laboratory for Inorganic Chemistry, H-1 112 Budapest, Budä̈rsi ut 45 (Hungary)

F. KILĀR

Eötvös Loränd University, Department of Plant Physiology, H-1088 Budapest, Muzeum krt 4/a (Hungary)

(Received 29 June 1979)

\section{ABSTRACT}

The in-plane vibrations of pyridine and its deuterated derivatives $\left(4-d_{1}, 2,6-d_{2}\right.$, $3,5-d_{2}$, and $d_{s}$ ) have been studied with the CNDO/2 force method. The calculated values of the force field scaled by five empirical parameters yield good agreement with the experimental spectra. The results seem to permit the reassignment of some bands.

\section{INTRODUCTION}

The knowledge of force constants and the prediction of vibrational spectra is of practical importance. If transferable force constants are known the vibrational spectra can be calculated [1]. The force field, determined from the experimental spectra, is unfortunately not transferable in general.

Convenient and transferable force constants reproducing the spectra are known in only a few cases, e.g. for paraffins [2] and for fluorobenzenes [3]. In other cases the great number of unknown parameters and the uncertain assignments render the determination of a consistent force field difficult.

Calculation of the spectra by quantum chemical methods overcomes the above difficulties. Ab initio calculations [4] give good results but their use is restricted to small molecules. For bigger molecules semi-empirical methods are used. The results of Török, Pulay and co-workers [5-9] show that the CNDO/2 parametrization procedure allows good agreement with the experimental spectra. The use of this method is especially important in the determination of pure deformational and deformational-stretching coupling force constants. The calculated absolute values of the force constants are higher than the real ones but their relative magnitudes are correct. After being scaled by empirical factors satisfactory force constants are obtained. For force constants corresponding to different types of internal coordinates different scaling factors are used. 
The objective of the present work was, apart from confirming the correctness of the method, to obtain a useful force field for pyridine and to check the foregoing assignments.

\section{METHOD}

In the force method $[5,10]$ the energy is calculated for distorted forms of the equilibrium position. The first derivatives, the forces on the atoms in these distorted configurations are calculated analytically while the force constants are then obtained by simple numerical derivation of the forces.

Using CNDO/2 wave functions no numerical instabilities appear if the distortion of the internal coordinates does not exceed $0.02-0.03 \AA$ or radian [9]. In the present study the change of the coordinates was unanimously $0.02 \AA$ or radian in positive and negative directions from the equilibrium position. A separate calculation was done for both directions to test the effect of anharmonicity.

On the basis of the calculations of Kozmutza and Pulay [6] and theoretical considerations of Schwendeman [11] it was concluded that experimental geometrical parameters would be more useful for these calculations than calculated ones. Thus, instead of using an energy-minimized geometry calculated by the CNDO/2 procedure, experimental data from a microwave spectrum were taken. The geometrical parameters of the equilibrium position given by $\mathrm{Bak}$ et al. [12] figure in Table 1 while the non-regular pyridine hexagon is shown in Fig. 1.

Pyridine and its derivatives considered here all belong to the point group $C_{2 v}$. Among their 19 in-plane normal modes of vibration 10 belong to the $A_{1}$ and 9 to the $B_{1}$ species. The internal coordinates used are listed in Table 2 and shown in Fig. 1.

\section{TABLE 1}

Cartesian coordinates of the atomic nuclei of pyridine (in $A$ ) in the coordinate system of Fig. 1 [12]

\begin{tabular}{llr}
\hline & $x$ & \multicolumn{1}{l}{$y$} \\
\hline $\mathrm{H}_{7}$ & 2.0557 & -1.2761 \\
$\mathrm{H}_{8}$ & 2.1526 & 1.2055 \\
$\mathrm{H}_{9}$ & 0.0 & 2.4924 \\
$\mathrm{~N}_{1}$ & 0.0 & -1.3949 \\
$\mathrm{C}_{2}$ & 1.1416 & -0.6929 \\
$\mathrm{C}_{3}$ & 1.1974 & 0.7005 \\
$\mathrm{C}_{4}$ & 0.0 & 1.4151 \\
\hline
\end{tabular}




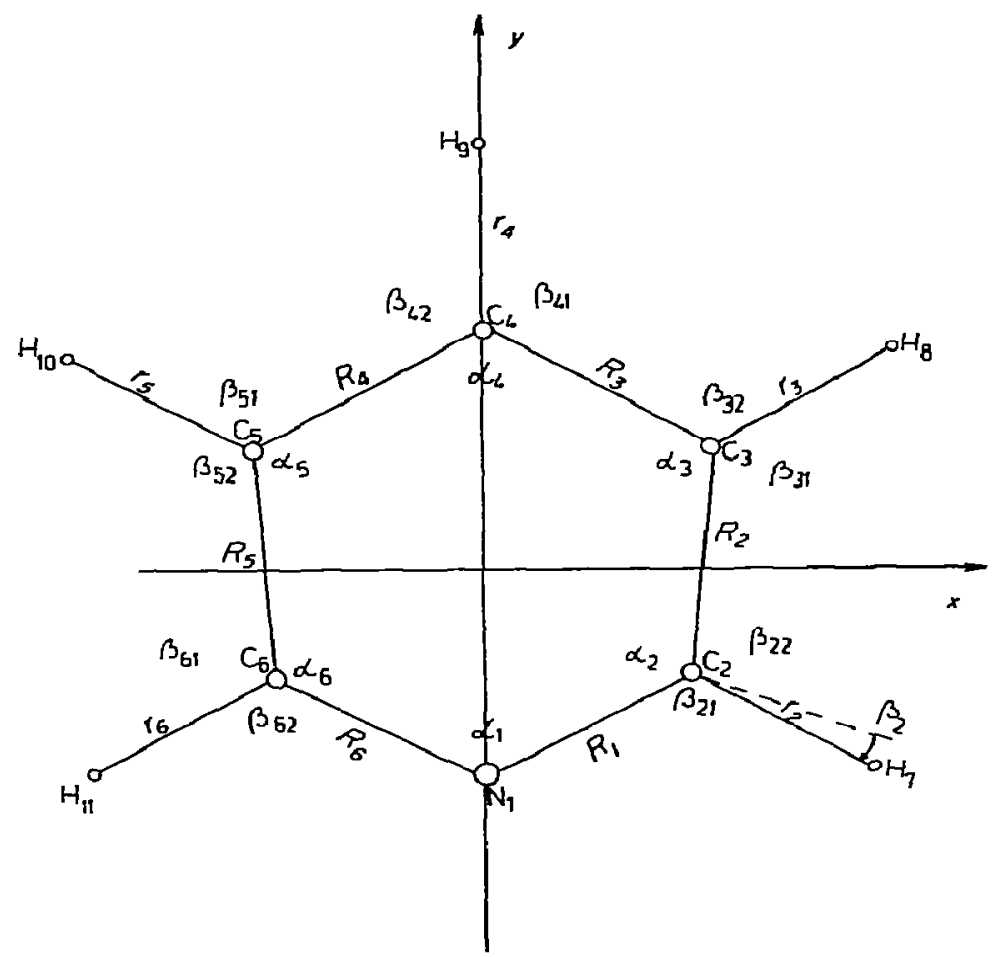

Fig. 1. Position of the atoms and internal coordinates in pyridine (see Tables 1 and 2)

TABLE 2

Internal coordinates

\begin{tabular}{|c|c|c|c|}
\hline $\begin{array}{l}\text { No. of } \\
\text { coordinates }\end{array}$ & Type & $\begin{array}{l}\text { Definition of } \\
\text { the coordinates }\end{array}$ & Significance \\
\hline $\begin{array}{l}1,2,3,4 \\
5,6\end{array}$ & stretching & $\Delta R_{i}(i=1 \ldots 6)$ & $\begin{array}{l}\text { change in the length } \\
\text { of the } \mathrm{C}_{2}-\mathrm{N}_{1} \text { resp. } \\
\mathrm{C}_{6}-\mathrm{N}_{1} \text { and of the } \\
\mathrm{C}_{i}-\mathrm{C}_{i-1}(i \neq 1,2) \\
\text { bonds }\end{array}$ \\
\hline $\begin{array}{l}7,8,9,10 \\
11\end{array}$ & stretching & $\Delta r_{i}(i=2 \ldots 6)$ & $\begin{array}{l}\text { change in the length } \\
\text { of the } \mathrm{C}-\mathrm{H}_{i+5} \text { bonds }\end{array}$ \\
\hline $\begin{array}{l}12,13,14 \\
15,16\end{array}$ & bending & $\beta_{i}=\beta_{i 2}-\beta_{i 1}(i=2 \ldots 6)$ & $\begin{array}{l}\text { change in the HCC } \\
\text { angles }\end{array}$ \\
\hline 17 & bending & $\tilde{\alpha}_{1}=\alpha_{1}-\alpha_{2}+\alpha_{3}-\alpha_{4}+\alpha_{5}-\alpha_{6}$ & $\begin{array}{l}\text { change in the CCC } \\
\text { angles }\end{array}$ \\
\hline 18 & bending & $\bar{\alpha}_{2}=2 \alpha_{1}-\alpha_{2}-\alpha_{3}+2 \alpha_{4}-\alpha_{5}-\alpha_{6}$ & $\begin{array}{l}\text { change in the CCC } \\
\text { angles }\end{array}$ \\
\hline 19 & bending & $\bar{\alpha}_{3}=\alpha_{2}-\alpha_{3}+\alpha_{5}-\alpha_{6}$ & $\begin{array}{l}\text { change in the } \mathrm{CCC} \\
\text { angles }\end{array}$ \\
\hline
\end{tabular}




\section{RESULTS AND DISCUSSION}

\section{Force field}

The method described above served for the calculation of a rough force field for pyridine. As already mentioned, these directly calculated CNDO/2 values must be adjusted using empirical factors to eliminate CNDOapproximation errors.

The scaling procedure has already been described [5-9]: the empirical factors in question are related to the different types of coordinates. The choice of coordinates is governed by theoretical considerations, those of Table 2 being set up in accordance with ref. 13. In the present case there are five factors which correspond, respectively, to $\mathrm{CH}$ stretching, $\mathrm{CC}$ stretching, $\mathrm{CN}$ stretching, $\mathrm{CCH}$ bending and $\mathrm{CCC}$ bending coordinates. The scaling factor $c_{i}$ corresponding to a given type of coordinate is obtained by dividing by the calculated value that experimental $F_{i i}$ element which seems to be the most reliable for the given coordinate. Then, all the calculated diagonal force

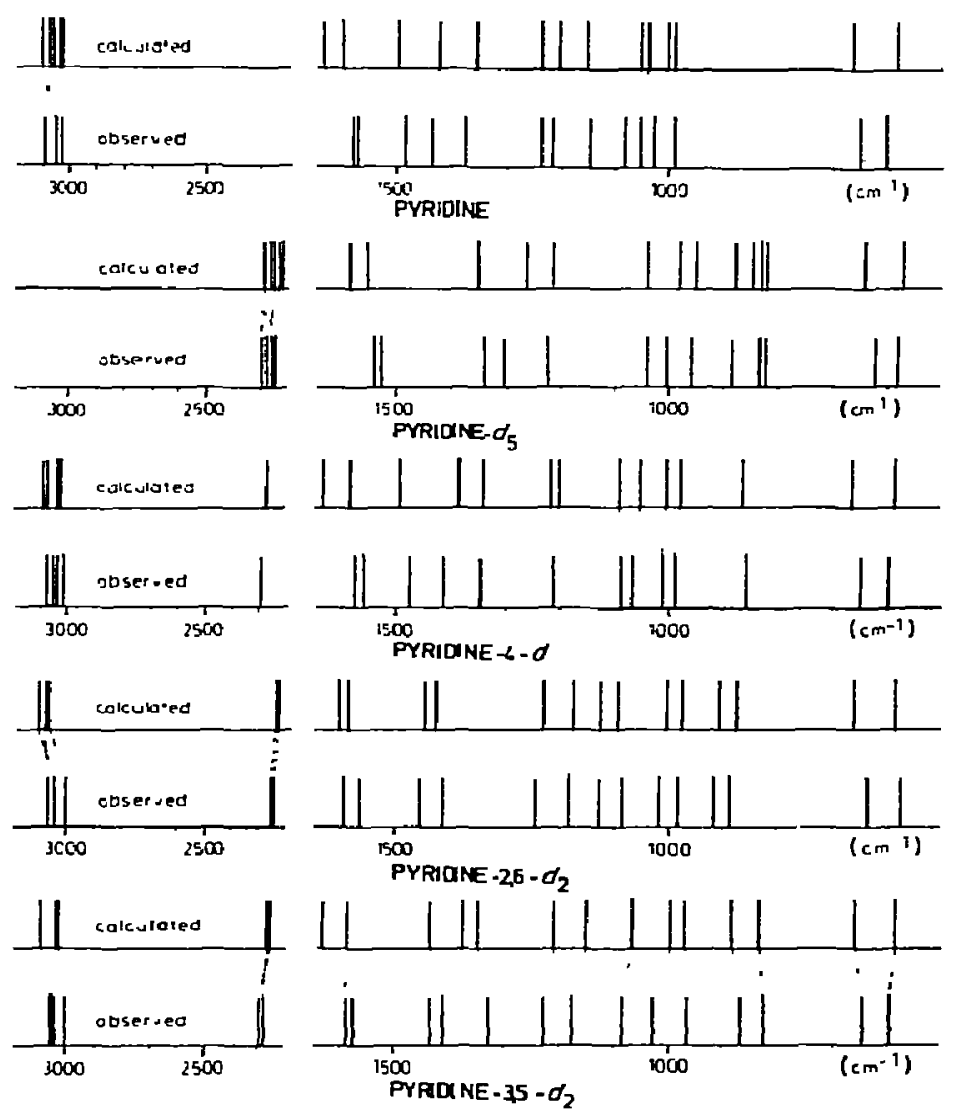

Fig. 2. Bar-diagram of the calculated and observed frequencies of pyridine and its deuterated derivatives (see Tables 3 and 5); dotted lines show correspondence. 

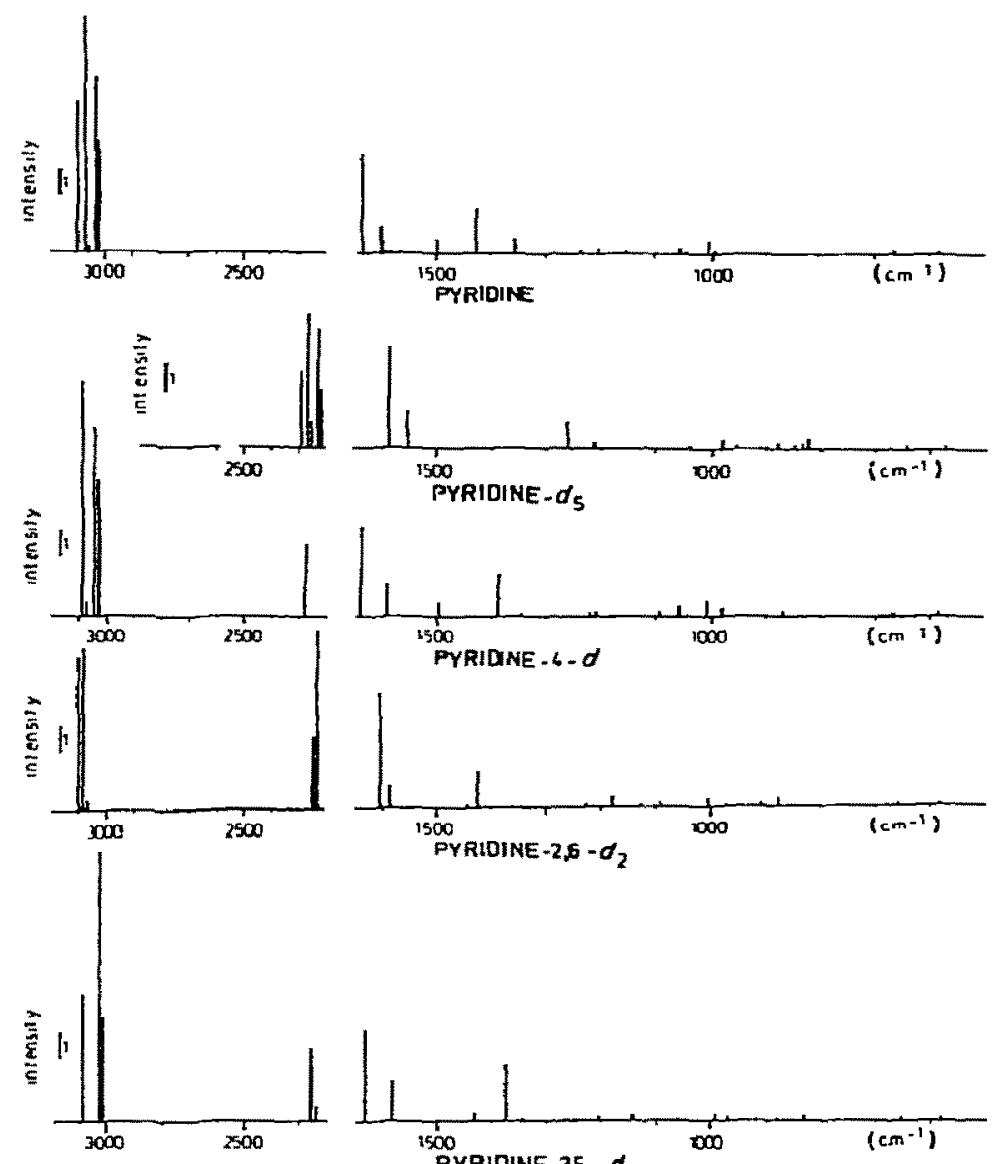

Fig. 3. Diagram of calculated intensities.

constants, including other symmetry species, are multiplied by the same factor $\left(c_{i}\right)$. The same procedure is repeated for the remaining four types of coordinates. The off-diagonal $F_{i j}$ are corrected by $\left(c_{i} c_{j}\right)^{\frac{1}{2}}$. Thus, the diagonal constants are experiment values while corrected theoretical values appear as off-diagonal constants in the force field.

Before evaluating the correcting factors for pyridine we checked whether the factors already known for benzene and its derivatives [9] could be applied. The similarity of the pyridine and benzene molecules, arising from the isoelectronicity of nitrogen and the $\mathrm{CH}$ group of benzene, has often been used in normal coordinate calculations (e.g., [14]). However, while in previous papers the force constants of benzene were applied for pyridine, in the present work a separate CNDO/2 calculation of the force field for pyridine was done. Only the known scaling factors of benzene [9] were employed: $c(\mathrm{CH})=c(\mathrm{CC})=0.382 ; c(\mathrm{CCH})=0.787 ; c(\mathrm{CCC})=1.19$. Unfortunately, the influence of the nitrogen atom is rather important, the deviation of the frequencies calculated in this way being large enough (see Table 3 ) to necessitate the use of other correcting factors. 
TABLE 3

Experimental and calculated frequencies of pyridine (in $\mathrm{cm}^{-1}$ ); the originally assigned values appear in parentheses

\begin{tabular}{|c|c|c|c|c|c|}
\hline Symmetry & $\begin{array}{l}\text { Notation } \\
\text { [19] }\end{array}$ & $\begin{array}{l}\text { Exp. } \\
{[19]}\end{array}$ & $\begin{array}{l}\text { Calculated } \\
\text { with scaling } \\
\text { factors of } \\
\text { ref. } 9\end{array}$ & $\begin{array}{l}\text { Present } \\
\text { calc. }\end{array}$ & $\begin{array}{l}\text { Character of } \\
\text { vibration from } \\
\text { the CNDO } / 2 \\
\text { force method }\end{array}$ \\
\hline \multirow[t]{10}{*}{$A_{1}$} & $\nu_{1}$ & 992 & 1028 & 993 & $\alpha(C C C),(v(C N), v(C C))$ \\
\hline & $\nu_{2}$ & 3054 & 3080 & 3067 & $\nu(\mathbf{C H})$ \\
\hline & $\nu_{6} a$ & 605 & 609 & 588 & $\alpha(\mathrm{CCC}),($ resp. $\alpha(\mathrm{NCC}))$ \\
\hline & $\nu_{8 \mathbf{a}}$ & 1583 & 1729 & 1637 & $v(\mathrm{CC})$ \\
\hline & $\nu_{9 a}$ & 1218 & 1224 & 1203 & $\beta(\mathrm{CH})$ \\
\hline & $v_{12}$ & 1029 & 1067 & 1004 & $\alpha(\mathrm{CCC}),($ resp. $\alpha(\mathrm{NCC}))$ \\
\hline & $\nu_{13}$ & 3054 & 3096 & 3092 & $\nu(\mathrm{CH})$ \\
\hline & $\nu_{18 a}$ & 1068 & 1103 & 1055 & $\beta(\mathrm{CH}), \nu(\mathrm{CN})$ \\
\hline & $\nu_{1 s a}$ & 1482 & 1530 & 1499 & $\beta(\mathrm{CH}), \nu(\mathrm{CN})$ \\
\hline & $\nu_{z 0 a}$ & 3036 & 3071 & 3037 & $\nu(\mathrm{CH})$ \\
\hline \multirow[t]{10}{*}{$B_{1}$} & $v_{3}$ & $\begin{array}{r}1235^{a} \\
(1217)\end{array}$ & 1322 & 1236 & $\nu(\mathrm{CC}), \beta(\mathrm{CH})$ \\
\hline & $\nu_{6 b}$ & 652 & 691 & 669 & $\alpha(\mathrm{CCC})$ \\
\hline & $\nu_{7 \mathrm{~b}}$ & $\begin{array}{c}3036^{\mathrm{b}} \\
(3054)\end{array}$ & 3075 & 3038 & $\nu(\mathrm{CH})$ \\
\hline & $\nu_{5 b}$ & 1572 & 1689 & 1599 & $\nu(\mathrm{CN}), \nu(\mathrm{CC})$ \\
\hline & $\nu_{14}$ & 1375 & 1353 & 1356 & $\nu(\mathrm{CN}), \beta(\mathrm{CH})$ \\
\hline & $\nu_{15}$ & 1148 & 1171 & 1157 & $\beta(\mathrm{CH})$ \\
\hline & $\nu_{1 \mathrm{sb}}$ & $1057^{a}$ & 1098 & 1044 & $\beta(\mathrm{CH})$ \\
\hline & & $(1068)$ & & & \\
\hline & $\nu_{19 \mathrm{~b}}$ & 1439 & 1456 & 1428 & $\beta(\mathbf{C H})$ \\
\hline & $\nu_{20 \mathrm{~b}}$ & 3083 & 3092 & 3072 & $\nu(\mathrm{CH})$ \\
\hline
\end{tabular}

aFrom ref. 24. bFrom ref. 21.

Introducing a new factor for the $\mathrm{CN}$ stretching coordinate and varying the others with a least squares method the following correction factors were obtained: $c(\mathrm{CN})=0.320 ; c(\mathrm{CC})=0.344 ; c(\mathrm{CH})=0.380 ; c(\mathrm{CCH})=0.813$ and $c(C C C)=1.14$. The experimental spectrum of pyridine and some deuterated derivatives $\left(d_{5} ; 4-d_{1} ; 2,6-d_{2}\right.$ and $\left.3,5-d_{2}\right)$ were taken into consideration for the above calculation.

As the error due to the CNDO-approximation is fairly systematic for stretching-type coordinates, it could be expected that the corresponding scaling factors are the same for different molecules. In fact, the value corresponding to the $\mathrm{CH}$ stretching coordinate is nearly the same as that employed for various molecules in refs. 6,8 and 9 but that for the CC stretching is influenced by the skeleton $\mathrm{N}$-atom and undergoes a change of $10 \%$. The error is, however, less systematic for bending coordinates and the variation of the corresponding scaling factors cannot be so easily explained.

It should be realised that this method of calculation is not just a mani- 
pulation of numbers: with five empirical parameters the complete force field is well reproduced, which can be seen by comparing the calculated and experimental frequencies (see later). However, many more parameters are needed for normal coordinate calculations.

The scaled $F$-matrix is represented in Table 4 . The original values (resulting directly from the CNDO/2 calculation) are given for the first column and those for the diagonal elements are given in parentheses. The rows refer to the coordinates of Table 2.

Comparing this force field with the normal coordinate calculations for benzene of Duinker and Mills [15], the results of Whiffen [16], or the CNDO/2 calculations of Fogarasi and Pulay [9], the present values seem to be very reasonable. However, the normal coordinate calculations of Long, Murfin and Thomas (LMT) [14], based on Whiffen's force field for benzene [16], show a surprising deviation. In their work, among other neglected factors, they considered the $\mathrm{CN}$ and $\mathrm{CC}$ bonds to be identical, and hence the values of the corresponding force constants of LMT to be the same. As the difference between the $\mathrm{CN}$ and $\mathrm{CC}$ bond lengths is at least $0.05 \AA$, the present distinction, i.e. a larger value for the force constant of the $C N$ stretching, seems to be more realistic. Also, while the other diagonal constants of Table 4 agree fairly well with those of LMT, the interaction constants differ significantly. There are many more non-zero terms in our Table 4: a number of interactions do not appear in [14] because of the neglected factors. On the other hand, in a number of cases the constants are of opposed sign (e.g., for $F_{13}$ we find a negative, LMT a positive value; even for benzene a negative value is suggested for meta-interaction by Scherer and Overend [17]). The present force field, which results from a separate calculation for pyridine, shows that the nitrogen influences the force field compared with benzene more than was expected earlier; pyridine has a more complex force field and some former simplifications are not justified.

\section{Assignments}

The primary importance of the present force constants is checking of previous assignments [18-24] . The scaled CNDO/2 force constants and dipole moment derivatives yield the frequencies and i.r. intensities shown in Tables 3,5 and 6 and in Figs. 2 and 3, respectively.

Our calculations for pyridine support the recent slight modifications, $\left(\nu_{3}\right.$ and $\left.\nu_{18}\right)$ of Suzuki and Orville-Thomas [24] and the earlier one $\left(\nu_{7 b}\right)$ of Wilmshurst and Bernstein (WB) [21], in the original assignment of Corrsin, Fax and Lord (CFL) [19], but no other changes in the assignment were necessary (see Table 3).

Good agreement was obtained for pyridine- $4-d_{1}$ with the experimental results of Anderson et al. [20] modified with Raman data ( $\nu_{2}$ and $\left.\nu_{12}\right)$ by WB [21] (Table 5).

In the cases of pyridine-2,6-d and 3,5-d the assignment of WB [21] was 
TABLE 4

In-plane force constants of pyridine (in mdyn $\AA^{-1}$ ); values in parentheses are directly calculated, non-scaled CNDO-values

\begin{tabular}{|c|c|c|c|c|c|c|c|c|}
\hline Notation & $\Delta R_{1}$ & $\Delta R_{2}$ & $\Delta R_{3}$ & $\Delta R_{4}$ & $\Delta R_{s}$ & $\Delta R_{6}$ & $\Delta r_{2}$ & $\Delta r_{3}$ \\
\hline$\Delta R_{1}$ & $\begin{array}{c}7.155 \\
(22.337)\end{array}$ & & & & & & & \\
\hline$\Delta R_{2}$ & $\begin{array}{c}0.833 \\
(2.512)\end{array}$ & $\begin{array}{c}6.155 \\
(17.910)\end{array}$ & & & & & & \\
\hline$\Delta R_{3}$ & $\begin{array}{c}-0.405 \\
(-1.222)\end{array}$ & 0.757 & $\begin{array}{c}6.208 \\
(18.063)\end{array}$ & & & & & \\
\hline$\Delta R_{4}$ & $\begin{array}{c}0.452 \\
(1.365)\end{array}$ & -0.383 & 0.763 & $\begin{array}{c}6.208 \\
(18.063)\end{array}$ & & & & \\
\hline$\Delta R_{s}$ & $\begin{array}{c}-0.397 \\
(-1.198)\end{array}$ & 0.381 & -0.383 & 0.757 & $\begin{array}{r}6.155 \\
(17.910)\end{array}$ & & & \\
\hline$\Delta R_{6}$ & $\begin{array}{c}0.833 \\
(2.601)\end{array}$ & $\multimap 0.397$ & 0.452 & -0.405 & 0.833 & $\begin{array}{r}7.155 \\
(22.337)\end{array}$ & & \\
\hline$\Delta r_{2}$ & $\begin{array}{c}0.227 \\
(0.652)\end{array}$ & 0.181 & 0.015 & -0.026 & -0.023 & 0.014 & $\begin{array}{c}5.106 \\
(13.459)\end{array}$ & \\
\hline$\Delta r_{3}$ & $\begin{array}{c}0.016 \\
(0.046)\end{array}$ & 0.162 & 0.175 & 0.013 & -0.020 & -0.021 & 0.0 & $\begin{array}{r}5.201 \\
(13.709)\end{array}$ \\
\hline$\Delta r_{4}$ & $\begin{array}{l}-0.018 \\
(-0.052)\end{array}$ & 0.012 & 0.175 & 0.175 & 0.012 & -0.018 & 0.003 & 0.0 \\
\hline$\Delta r_{s}$ & $\begin{array}{c}-0.021 \\
(-0.060)\end{array}$ & -0.020 & 0.013 & 0.175 & 0.162 & 0.016 & 0.001 & 0.002 \\
\hline$\Delta r_{6}$ & $\begin{array}{c}0.014 \\
(0.040)\end{array}$ & -0.023 & -0.026 & 0.015 & 0.181 & 0.227 & 0.002 & 0.001 \\
\hline$\beta_{2}$ & $(-0.183$ & 0.161 & 0.009 & 0.002 & 0.012 & -0.006 & $\longrightarrow 0.011$ & -0.006 \\
\hline$\beta_{3}$ & $(-0.018$ & $\longrightarrow 0.159$ & 0.165 & 0.007 & -0.011 & 0.008 & 0.008 & -0.001 \\
\hline$\beta_{4}$ & $\begin{array}{c}0.005 \\
(0.009)\end{array}$ & -0.008 & -0.161 & 0.161 & 0.008 & -0.005 & -0.005 & 0.009 \\
\hline$\beta_{5}$ & $\begin{array}{l}-0.008 \\
(-0.017)\end{array}$ & 0.011 & -0.007 & -0.165 & 0.159 & 0.018 & 0.0 & -0.005 \\
\hline$\beta_{6}$ & $\begin{array}{c}0.006 \\
(0.012)\end{array}$ & -0.012 & -0.002 & -0.009 & -0.161 & 0.183 & 0.005 & 0.0 \\
\hline $\bar{\alpha}_{1}$ & $\begin{array}{c}0.039 \\
(0.064)\end{array}$ & $\longrightarrow 0.017$ & -0.010 & -0.010 & -0.017 & 0.039 & 0.150 & -0.141 \\
\hline$\vec{\alpha}_{2}$ & $\begin{array}{c}0.151 \\
(0.251)\end{array}$ & -0.101 & 0.067 & 0.067 & $\longrightarrow 0.101$ & 0.151 & 0.078 & 0.079 \\
\hline $\bar{\alpha}_{3}$ & $\begin{array}{c}0.183 \\
(0.304)\end{array}$ & -0.018 & -0.148 & 0.148 & 0.018 & -0.183 & $\rightarrow 0.154$ & 0.131 \\
\hline
\end{tabular}

taken as a basis (Table 5). Two changes are suggested for both of them. For $2,6-d_{2}$ Zerbi et al. [23] propose the very weak $1345 \mathrm{~cm}^{-1}$ band $\left(\nu_{14}\left(B_{1}\right)\right.$ of ref. 21), not appearing in the gas phase, as an overtone of two out-of-plane frequencies and suggest the band of $1258 \mathrm{~cm}^{-1}$ for $\nu_{14}$. On the basis of Tables 5 and 6 , the attribution of the $1243 \mathrm{~cm}^{-1}$ band, which also appears in the Raman spectrum, seems to be more justified. Similarly, [23] suggests the band at $\sim 902 \mathrm{~cm}^{-1}$ for $\nu_{18 \mathrm{~b}}\left(B_{1}\right)$ instead of the $860 \mathrm{~cm}^{-1}$ band. Although $902 \mathrm{~cm}^{-1}$ is nearest our calculated value of $909 \mathrm{~cm}^{-1}$, the assignment is doubtful since the band at $915 \mathrm{~cm}^{-1}$, which appears in both i.r. liquid and vapor spectra, is equally supported by the present results; the $915 \mathrm{~cm}^{-1}$ band is preferred here.

While the present results for pyridine-3,5- $d_{2}$ confirm Zerbi's [23] proposition that the $\nu_{3}\left(B_{1}\right)$ mode should be reassigned and that the band at 


\begin{tabular}{lllllllllll}
\hline$\Delta r_{4}$ & $\Delta r_{5}$ & $\Delta r_{6}$ & $\beta_{2}$ & $\beta_{3}$ & $\beta_{4}$ & $\beta_{5}$ & $\beta_{6}$ & $\bar{\alpha}_{1}$ & $\bar{\alpha}_{2}$ & $\bar{\alpha}_{3}$ \\
\hline
\end{tabular}

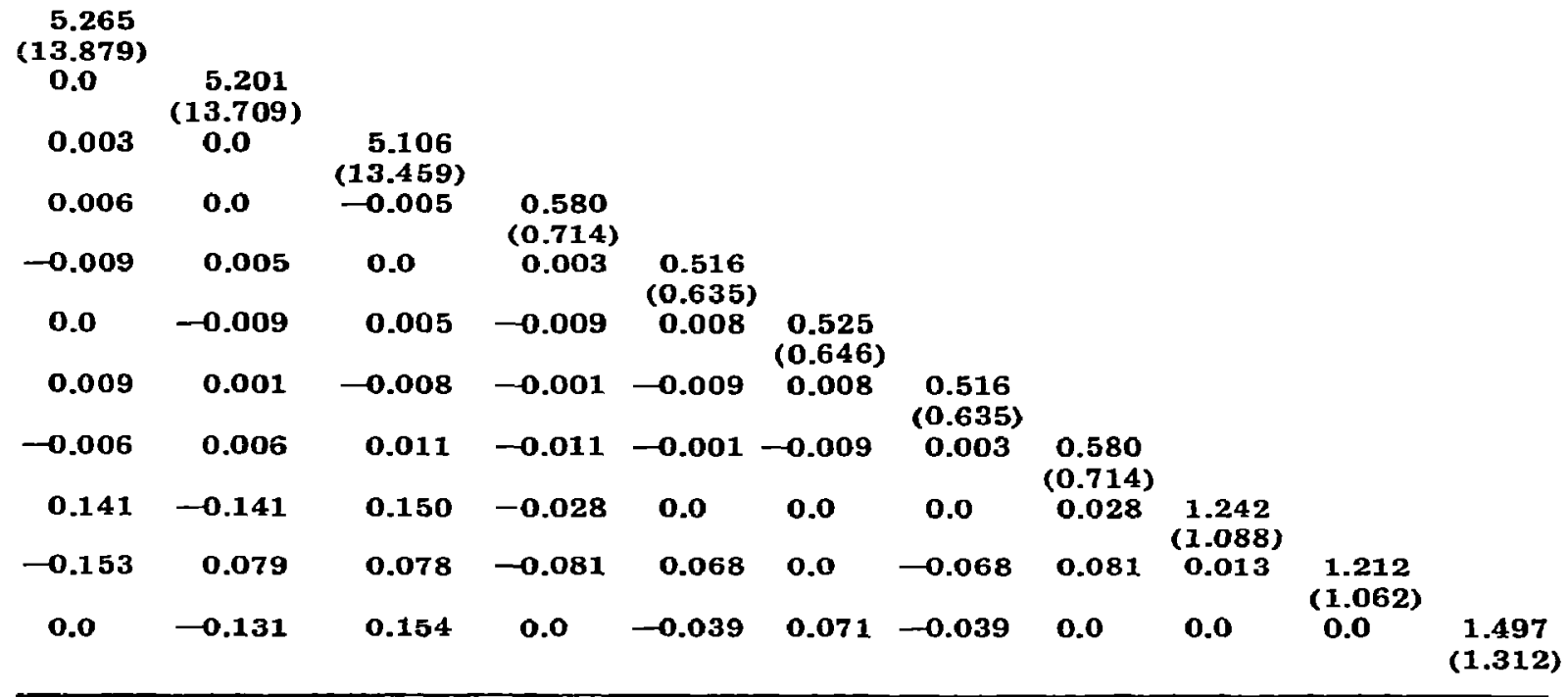

$947 \mathrm{~cm}^{-1}$ should be attributed to an out-of-plane mode instead (see also ref. 22), they do not confirm his assignment (i.e., the band at $897 \mathrm{~cm}^{-1}$ to $\nu_{3}\left(B_{1}\right)$ ). As shown in Table 5, the band at $1227 \mathrm{~cm}^{-1}$ should be assigned to $\nu_{3}\left(B_{1}\right)$ and the $897 \mathrm{~cm}^{-1}$ band to $\nu_{15}\left(B_{1}\right)$. The band at $1105 \mathrm{~cm}^{-1}$ (previously assigned to $\nu_{15}$ ) is attributed to a combination band of two out-of-plane frequencies: $\left[\nu_{4}+\nu_{16 b}\right] 391+713=1104 \mathrm{~cm}^{-1}$.

It is not self-evident that the $897 \mathrm{~cm}^{-1}$ band should be assigned to $\nu_{15}$. The calculated value of $881 \mathrm{~cm}^{-1}$ does not enable a choice to be made between the bands at $867 \mathrm{~cm}^{-1}\left(A_{2}\right.$ according to WB [21]) and $897 \mathrm{~cm}^{-1}$ ( $B_{2}$ according to WB [21]). If the band at $947 \mathrm{~cm}^{-1}$ corresponded to an $A_{2}$ mode [22], the band at $867 \mathrm{~cm}^{-1}$ should be assigned to $\nu_{15}$. However, an $A_{2}$ fundamental of the $C_{2 v}$ point group appears only in the Raman spectrum and not in the infrared: the band at $947 \mathrm{~cm}^{-1}$, however, shows no Raman activity and is assigned to a $B_{2}$ fundamental, and hence the $897 \mathrm{~cm}^{-1}$ band to $\nu_{15}$. 


\section{TABLE 5}

Experimental and calculated frequencies of deuterated pyridines of $C_{2 v}$ symmetry (in $\mathrm{cm}^{-1}$ ); the originally assigned values appear in parentheses

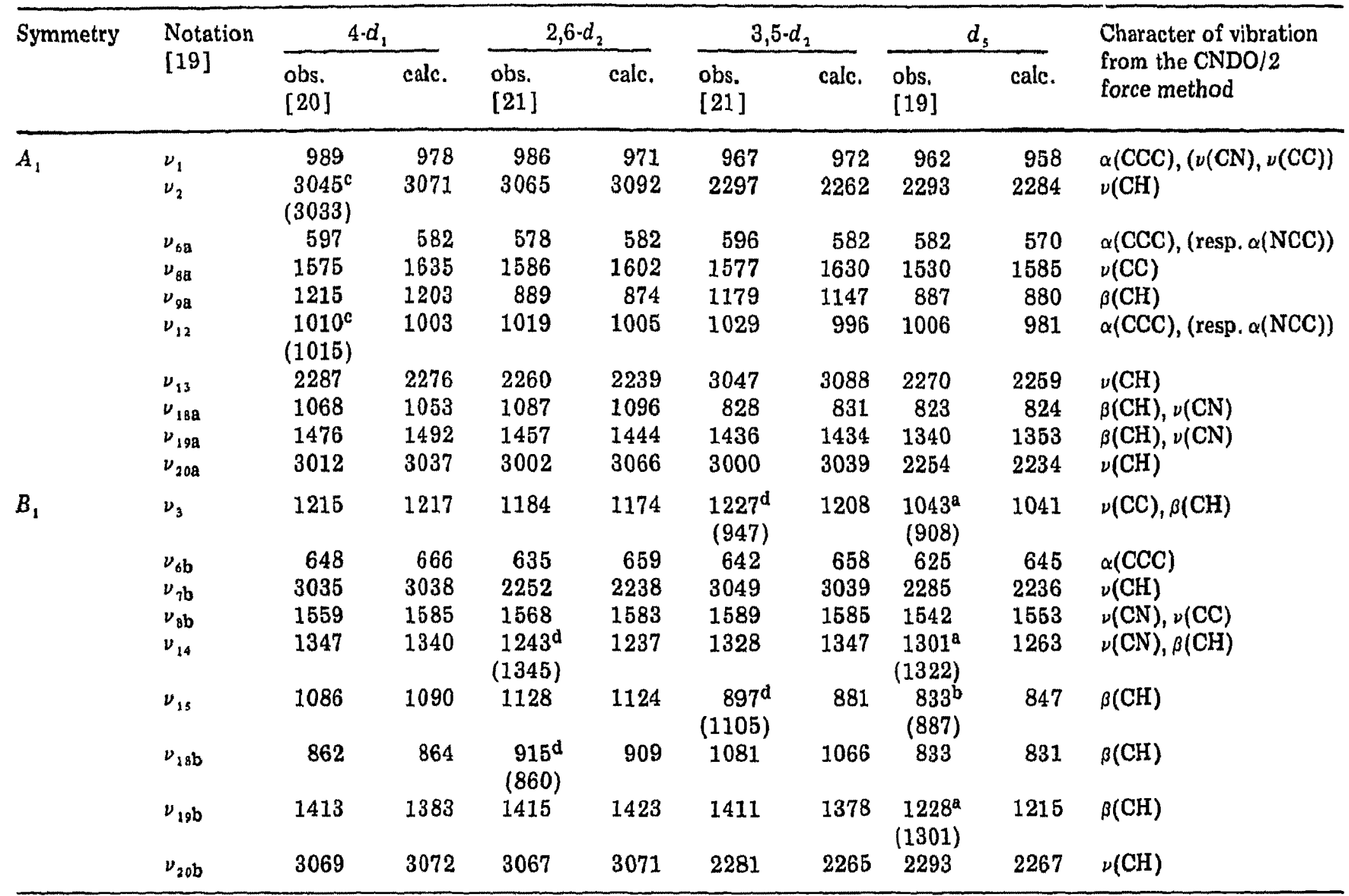

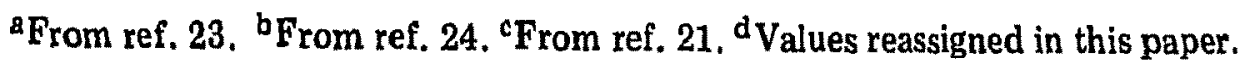


TABLE 6

Calculated intensities (in $\mathbf{c m ~} \mathbf{~ m m o l}^{-1}$ )

\begin{tabular}{|c|c|c|c|c|c|c|}
\hline \multirow{2}{*}{$\begin{array}{l}\text { Symmetry } \\
\nu_{2}\end{array}$} & \multirow{2}{*}{$\begin{array}{l}\text { Notation } \\
\text { [19] }\end{array}$} & \multicolumn{5}{|c|}{ Pyridine } \\
\hline & & $d_{\mathrm{o}}$ & $4-d_{1}$ & $2,6-d_{2}$ & $3,5-d_{2}$ & $d_{5}$ \\
\hline \multirow{10}{*}{$A_{1}$} & $\nu_{1}$ & 698 & 182 & 28 & 5 & 61 \\
\hline & $\nu_{2}$ & 9603 & 511 & 6644 & 11063 & 5616 \\
\hline & $\nu_{6 a}$ & 36 & 29 & 42 & 24 & 23 \\
\hline & $\nu_{\mathrm{sa}}$ & 4164 & $\mathbf{3 8 7 4}$ & 4761 & 3853 & 4247 \\
\hline & $\nu_{9 a}$ & 79 & 80 & 12 & 286 & 420 \\
\hline & $\nu_{12}$ & 8 & 635 & 2 & 225 & 4 \\
\hline & $\nu_{13}$ & 4691 & 3118 & 7276 & 604 & 2526 \\
\hline & $v_{18 \mathrm{a}}$ & 451 & 396 & 395 & 395 & 74 \\
\hline & $v_{19 a}$ & 604 & 598 & 0 & 592 & 0 \\
\hline & $\nu_{20 a}$ & 7892 & 5211 & 2946 & 3096 & 4929 \\
\hline \multirow{9}{*}{$B_{1}$} & $v_{3}$ & 20 & 57 & 463 & 252 & 4 \\
\hline & $\nu_{6 b}$ & 98 & 109 & 84 & 103 & 99 \\
\hline & $\nu_{7 \mathrm{~b}}$ & 64 & 7892 & 56 & 4181 & 1057 \\
\hline & $\nu_{8 b}$ & 1029 & 1500 & 980 & 1192 & 1646 \\
\hline & $v_{14}$ & 570 & 40 & 52 & 8 & 229 \\
\hline & $\nu_{15}$ & 192 & 144 & 283 & 0 & 14 \\
\hline & $\nu_{18 b}$ & 35 & 35 & 300 & 325 & 443 \\
\hline & $\nu_{19 b}$ & 1924 & 1848 & 1527 & 2303 & 1049 \\
\hline & $\nu_{20 b}$ & 6020 & 9597 & 6344 & 5281 & 3043 \\
\hline
\end{tabular}

In the case of pyridine- $d_{5}$, the calculated frequencies support the reassignments by Zerbi et al. [23] of the $\nu_{3}\left(B_{1}\right), \nu_{14}\left(B_{1}\right)$ and $\nu_{19 b}\left(B_{1}\right)$ modes, and that by Suzuki and Orville-Thomas [24] of the $\nu_{15}\left(B_{1}\right)$ mode of the original CFL assignment [19] (Table 5).

In conclusion, the mean deviation for the 95 frequencies is $18 \mathrm{~cm}^{-1}$, which proves that useful results can be obtained by employing only 5 parameters.

\section{ACKNOWLEDGEMENTS}

The authors are grateful to Prof. F. Török for suggesting this study and to Dr. P. Pulay for providing his computational programs, for helpful and stimulating discussions and for suggestions regarding the manuscript. Dr. G. Pongor is thanked for having lent his least square fitting program.

\section{REFERENCES}

1 E. B. Wilson, Jr., J. C. Decius and P. C. Cross, Molecular Vibrations, 1st edn., McGrawHill, New York, 1955.

2 J. H. Schachtschneider and R. G. Snyder, Spectrochim. Acta, 19 (1963) 85.

3 R. A. R. Pearce, D. Steele and K. Radcliffe, J. Mol. Spectrose., 15 (1973) 409.

4 P. Pulay, Mol. Phys., 17 (1969) 197. 
5 P. Pulay and F. Török, Mol. Phys., 25 (1973) 1153.

$6 \mathrm{~K}$. Kozmutza and P. Pulay, Theor. Chim. Acta, 37 (1975) 67.

7 F. Török, Á. Hegedüs, K. Kósa and P. Pulay, J. Mol. Struct., 32 (1976) 93.

8 Yu. Panchenko, P. Pulay and F. Török, J. Mol. Struct., 34 (1976) 283.

9 G. Fogarasi and P. Pulay, J. Mol. Struct., 39 (1977) 275.

10 P. Pulay, in H. F. Schaefer (Ed.), Modern Theoretical Chemistry, Vol. IV, Plenum, New York, 1977.

11 R. H. Schwendeman, J. Chem. Phys., 44 (1966) 2115.

12 B. Bak, L. Hansen-Nygaard and J. Rastrup-Andersen, J. Mol. Spectrose., 2 (1958) 361.

13 P. Pulay, G. Fogarasi, F. Pang and J. E. Boggs, J. Am. Chem. Soc., 101 (1979) 2550.

14 D. A. Long, F. S. Murfin and E. L. Thomas, Trans. Faraday Soc., 59 (1963) 12, 183.

15 J. C. Duinker and I. M. Mills, Spectrochim. Acta, Part A, 24 (1968) 417.

16 D. H. Whiffen, Philos. Trans. R. Soc. London, Ser. A, 248 (1955) 131.

17 J. R. Scherer and J. Overend, Spectrochim. Acta, 17 (1961) 719.

18 C. H. Kline and J. Turkevich, J. Chem. Phys., 12 (1944) 300.

19 L. Corrsin, B. J. Fax and R. C. Lord, J. Chem. Phys., 21 (1953) 1170.

20 F. A. Anderson, B. Bak, S. Brodersen and J. Rastrup-Andersen, J. Chem. Phys., 23 (1955) 1047.

21 J. K. Wilmsh urst and H. J. Bernstein, Can. J. Chem., 35 (1957) 1183.

22 M. A. Kovner, Yu. S. Korostelev and V. I. Berezin, Opt. Spectrosk., (Russ.), 10 (1961) 457.

23 G. Zerbi, B. Crawford, Jr. and J. Overend, J. Chem. Phys., 38 (1963) 127.

24 S. Suzuki and W. J. Orville-Thomas, J. Mol. Struct., 37 (1977) 321. 